\title{
Hepatotoxicidad grave inducida por sertralina
}

\author{
Nicolás Vargas P. ${ }^{1,2}$, Sergio Illanes D. ${ }^{2}$, Lorna Galleguillos G. $^{2}$ y Felipe Moscoso.$^{3}$
}

\footnotetext{
${ }^{1}$ Residente de Neurología. Facultad de Medicina, Universidad del Desarrollo. Santiago, Chile. ${ }^{2}$ Servicio de Neurología, Departamento de Neurología y Psiquiatría, Clínica Alemana de Santiago. Santiago, Chile. Departamento de Gastroenterología, Clínica Alemana de Santiago. Santiago, Chile.

Declaraciones Los autores declaran no tener conflictos de intereses.

El paciente firma

el formulario especificado para darnos su aprobación para la publicación del caso.

No recibimos ningún tipo de financiación

Todos los autores contribuyeron de la

misma manera al proceso de escritura del artículo.
}

Recibido: 22 de mayo 2019

Aceptado: 6 julio 2020

Correspondencia a: Dr. Nicolás Vargas nvargasp@udd.c

\section{Sertraline-induced severe hepatotoxicity}

We report the case of a 19-year-old patient, with a history of traumatic liver damage, but with a normal liver profile at her first discharge; 1 month after the event, with post-traumatic stress disorder, treatment with 25 $\mathrm{mg}$ of sertraline was started every day; one month later, she develops severe hepatotoxicity without a specific etiology. According to the Naranjo algorithm, it is attributed as a probable case of sertraline hepatotoxicity. Management is carried out with support measures and suspension of the medication, and the patient recovers until she is asymptomatic, currently has normal liver tests.

Key words: Sertraline, drug induced liver injury, hepatotoxicity.

\section{Resumen}

Reportamos el caso de una paciente de 19 años, con antecedentes de daño hepático traumático, pero con un perfil hepático normal en su primer alta; después de 1 mes del evento, con trastorno de estrés postraumático se inició tratamiento con $25 \mathrm{mg}$ diarios de sertralina; un mes después, desarrolla una hepatotoxicidad severa sin etiología determinada. De acuerdo con el algoritmo de Naranjo, se atribuye como caso probable de hepatotoxicidad por sertralina. El manejo se realiza con medidas de apoyo y suspensión del medicamento, y la paciente se recupera hasta que se encuentra asintomática, actualmente tiene pruebas hepáticas normales.

Palabras clave: Sertralina, lesión hepática inducida por sertralina, hepatotoxicidad.

\section{Introducción}

El uso de medicamentos implica el monitoreo de reacciones adversas que pueden presentarse en los pacientes. En el caso particular de la toxicidad hepática, podemos consultar el sitio web de Livertox que pertenece al Instituto Nacional de Salud de los Estados Unidos de América (NIH por sus siglas en inglés) ${ }^{1}$, en el cual se puede encontrar el resumen de la información reportada de daño hepático atribuible al uso de determinados medicamentos, suplementos dietéticos o herbales.

En el caso particular de la sertralina, las contraindicaciones no incluyen a los pacientes con alteraciones hepáticas, ni la recomendación de controlar la aparición de síntomas relacionados con el empeoramiento de la función hepática, principalmente debido a la ausencia de información en estos contextos ${ }^{2}$.

\section{Reporte de un caso}

Paciente femenina de 19 años, anteriormente sana, sufre lesiones por aplastamiento en un lugar abarrota- do de personas, y se la encuentra sin respuesta verbal u ocular, pero localiza el estímulo doloroso, con un 7 en la escala de coma de Glasgow. Se realiza intubación orotraqueal y se la transfiere a un servicio de salud, donde se realiza una tomografía computarizada (TC) de cabeza y cuello, sin evidencia de lesión traumática. Es evaluada por neurocirugía, que indica un retiro progresivo de la sedoanalgesia y la extubación.

Al encontrarse en vigilia, refiere dolor abdominal, y en el examen físico presenta dolor a la palpación en el hipocondrio derecho; la TC de abdomen describe una laceración hepática extensa, hematoma del segmento IV-VIII y del segmento VII, hematoma subcaspular, con poco líquido peritoneal libre; adicionalmente elevación de las pruebas hepáticas, de patrón mixto. Cirugía considera que no tiene indicación quirúrgica y continúa en tratamiento médico, consistente en manejo del dolor, con paracetamol $1 \mathrm{~g}$ cada $8 \mathrm{~h}$, metamizol $4 \mathrm{~g}$ diluidos en $250 \mathrm{ml}$ de suero fisiológico administrados en $24 \mathrm{~h}$, omeprazol $40 \mathrm{mg}$ por vía oral cada $24 \mathrm{~h}$, y cetirizina $10 \mathrm{mg}$ por vía oral cada día.

Se evalúa por Neurología, paciente tiene amnesia del evento, y se encuentra muy repetitiva. Presenta 
mejoría progresiva, al $7^{\circ}$ día de evolución con disminución del dolor por lo que se cambia a analgesia oral, paracetamol $1 \mathrm{~g}$ cada $8 \mathrm{~h}$. Una semana después con lesiones hepáticas estables y pruebas de laboratorio normales, es dada de alta solamente con paracetamol $1 \mathrm{~g}$ por vía oral cada $8 \mathrm{~h}$ en caso de dolor.

Un mes más tarde, acude a control con Neurología, sin dolor, ni otros síntomas físicos, pero manifiesta importante ansiedad, principalmente relacionada con algunos recuerdos diferidos del evento; y con examen físico normal y pruebas de laboratorios de control normales (incluidas las pruebas hepáticas), se plantea trastorno de estrés postraumático y se inicia tratamiento con sertralina $25 \mathrm{mg}$ diarios.

Un mes después del inicio del tratamiento, la paciente se pone en contacto con el neurólogo e informa que durante 2 semanas ha tenido malestar, astenia y alteración del gusto, y que durante 4 días ha notado ictericia en las escleróticas y dolor abdominal leve, así como un episodio de emesis. Niega fiebre, coluria o acolia. Niega uso de otros medicamentos diferentes a la sertralina (se interroga dirigidamente sobre uso de analgésicos, ansiolíticos, drogas, u homeopatía). El examen físico muestra ictericia en las escleróticas, así como dolor a palpación superficial en el abdomen, principalmente en el hipocondrio derecho. El laboratorio muestra bilirrubina (BT) $10,7 \mathrm{mg} / \mathrm{dL}$, bilirrubina directa (BD) $9,05 \mathrm{mg} / \mathrm{dL}$, aspartato aminotransferasa (TGO) $2359 \mathrm{UI} / \mathrm{L}$, alanina aminotransferasa (TGP) $2076 \mathrm{UI} / \mathrm{L}$, fosfatasa alcalina (FA) $201 \mathrm{UI} / \mathrm{L}$, gamma glutamil transferasa (GGT) $129 \mathrm{UI} / \mathrm{L}$, tiempo de protrombina (PT) 38\% y el INR de 2,1. El resultado del hemograma se considera normal. Hematíes $4.440 .000 / \mathrm{mm}^{3}$, hemoglobina $12,5 \mathrm{~g} / \mathrm{dL}$, hematocrito 37,6 , leucocitos $6.200 / \mathrm{mm}^{3}$, recuento absoluto de neutrófilos $4.414 / \mathrm{mm}^{3}(71,2 \%)$, recuento absoluto de linfocitos $980 / \mathrm{mm}^{3}(15,8 \%)$, recuento absoluto de monocitos $675 / \mathrm{mm}^{3}(10,9 \%)$, recuento absoluto de eosinóofilos $93 / \mathrm{mm}^{3}(1,5 \%)$, recuento absoluto de basófilos $37 / \mathrm{mm}^{3}(0,6 \%)$, plaquetas $189.000 / \mathrm{mm}^{3}$, velocidad de sedimentación globular $2 \mathrm{~mm} / \mathrm{h}$. Se realizó una nueva TC del abdomen y la pelvis, que informa edema periportal bilateral y de la pared vesicular con vesícula colapsada y tamaño reducido de hematomas hepáticos conocidos, hallazgos compatibles con hepatitis.

Con el análisis clínico, de laboratorio y de imágenes, se sospecha una lesión hepática aguda grave y se amplia estudio con un perfil infeccioso que incluye IgM hepatitis A negativa, antígeno de superficie de hepatitis B no reactivo, anticore hep. B negativo, anticuerpos anti hepatitis $\mathrm{C}$ negativo, PCR hepatitis $\mathrm{E}$ negativo, IgM, IgG y PCR sérica de citomegalovirus negativo, IgM contra cápside virus Epstein Barr negativo, IgG anti cápside virus Epstein Barr positivo, IgM, IgG, PCR sérica virus del herpes I y II negativo y con PCR sérica varicela negativa, descartando en su mayoría las causas de patología hepática infecciosa aguda.

Se solicita perfil inmunológico, el cual es normal (incluidos los anticuerpos antinucleares ANA, ANCA, Ro, La, factor reumatoide, C3, C4, anticuerpos contra el músculo liso y mitocondrial, e inmunoglobulinas cuantitativas); lipasa, amilasa, hierro y ceruloplasmina fueron también normales.

Debido a la disminución de las lesiones hepáticas traumáticas anteriores, la presentación clínica y paraclínica actual, acompañada del inicio de sertralina 1 mes antes, se evalúa el caso con la escala de probabilidad de reacción adversa al fármaco o algoritmo de Naranjo, obteniéndose una puntuación total de 7 (Tabla 1), clasificándose como caso probable; se suspende este medicamento.

Se indicaron medidas de apoyo, lo que mejora significativamente la sintomatología, se realizan pruebas seriadas de hígado, en las que se observa que la BT y el BD aumentaron hasta el día 7, después de lo cual disminuyen; pero las transaminasas presentan una disminución progresiva desde el ingreso (Tabla 2).

Tabla 1. Algoritmo de Naranjo, aplicado a caso clínico, con resultado de 7 puntos

\begin{tabular}{|c|c|c|c|}
\hline \multicolumn{4}{|l|}{ Algoritmo de naranjo } \\
\hline Pregunta & Sí & No & No sabe \\
\hline $\begin{array}{l}\text { 1. ¿Existen notificaciones concluyentes sobre esta } \\
\text { reacción? }\end{array}$ & 1 & 0 & 0 \\
\hline $\begin{array}{l}\text { 2. ¿Se produjo la RA después de administrar el } \\
\text { fármaco sospechoso? }\end{array}$ & 2 & -1 & 0 \\
\hline $\begin{array}{l}\text { 3. ¿Mejoró la RA tras suspender la } \\
\text { administración del fármaco o tras administrar } \\
\text { un antagonista específico? }\end{array}$ & 1 & 0 & 0 \\
\hline $\begin{array}{l}\text { 4. ¿Reapareció la RA tras readministración del } \\
\text { fármaco? }\end{array}$ & 2 & -1 & 0 \\
\hline $\begin{array}{l}\text { 5. ¿Existen causas alternativas (diferentes } \\
\text { del fármaco) que podrían haber causado la } \\
\text { reacción por sí misma? }\end{array}$ & -1 & 2 & 0 \\
\hline 6. ¿Reapareció la RA tras administrar placebo? & -1 & 1 & 0 \\
\hline $\begin{array}{l}\text { 7. ¿Se detectó el fármaco en la sangre (o en otros } \\
\text { fluidos) en concentraciones tóxicas? }\end{array}$ & 1 & 0 & 0 \\
\hline $\begin{array}{l}\text { 8. ¿Fue la reacción más severa al aumentar la } \\
\text { dosis o menos severa al disminuirla? }\end{array}$ & 1 & 0 & 0 \\
\hline $\begin{array}{l}\text { 9. ¿Tuvo el paciente alguna reacción similar } \\
\text { causada por el mismo fármaco u otro } \\
\text { semejante en cualquier exposición anterior? }\end{array}$ & 1 & 0 & 0 \\
\hline $\begin{array}{l}\text { 10. ¿Se confirmó el acontecimiento adverso por } \\
\text { cualquier tipo de evidencia objetiva? }\end{array}$ & 1 & 0 & 0 \\
\hline Puntuación total & & & \\
\hline
\end{tabular}




\section{Caso clínico}

Tabla 2. Cambios evolutivos en las pruebas hepáticas

\begin{tabular}{|lccccccc|}
\hline Pruebas hepáticas & $\begin{array}{c}\text { Primer } \\
\text { alta }\end{array}$ & $\begin{array}{c}\text { Segunda } \\
\text { admisión }\end{array}$ & $\begin{array}{c}\text { Tercer día } \\
\text { evolución }\end{array}$ & $\begin{array}{c}\text { Quinto día } \\
\text { evolución }\end{array}$ & $\begin{array}{c}\text { Séptimo día } \\
\text { evolución }\end{array}$ & $\begin{array}{c}\text { Alta } \\
\text { definitiva }\end{array}$ & $\begin{array}{c}\text { Primer } \\
\text { control }\end{array}$ \\
\hline BT (mg/dL) & 0,17 & 10,77 & 11,55 & 15,24 & 16 & 11,84 & 2,5 \\
BD (mg/dL) & & 9,05 & 10,1 & 12,85 & 13,77 & 10,35 & 2,13 \\
\hline TGO (UI/L) & 23 & 2359 & 1959 & 1916 & 1642 & 960 & 86 \\
TGP (UI/L) & 31 & 2076 & 1802 & 1686 & 1448 & 936 & 122 \\
\hline FA (UI/L) & 100 & 129 & 113 & 179 & 162 & 144 & 80 \\
GGT (UI/L) & 100 & 201 & 181 & 97 & 84 & 90 \\
\hline PT (\%) & 70 & 38 & 47 & 41 & 48 & 53 & 77 \\
INR & 1,2 & 2,1 & 1,8 & 2 & 1,8 & 1,6 & 1,2 \\
\hline
\end{tabular}

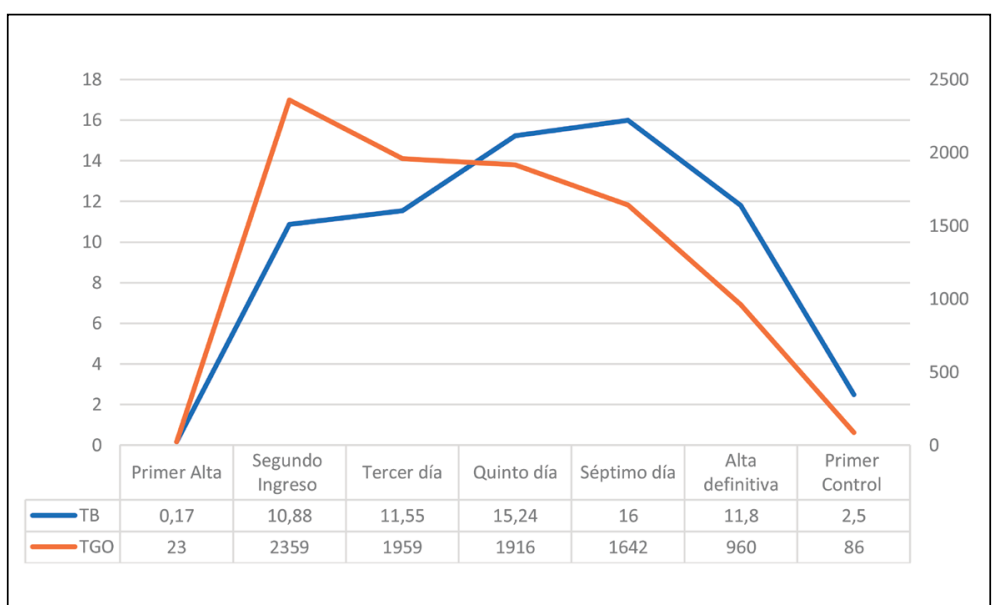

Figura 1. Comportamiento en el tiempo de los valores bilirrubina total (BT) frente a los valores de aspartato aminotransferasa (TGO).

A los 11 días de evolución, al estar asintomática y con pruebas hepáticas con marcado descenso progresivo, se le ordena regresar a casa, con la advertencia de no volver a usar medicamentos del grupo de inhibidores selectivos de la recaptación de serotonina (ISRS).

En una visita ambulatoria 1 mes después de la afección hepática, la paciente permanece asintomática, y las pruebas hepáticas disminuyen casi a valores normales (Figura 1).

\section{Discusión}

La sertralina es un medicamento que pertenece al grupo de los ISRS, usado principalmente como tratamiento en trastornos depresivos, ansiosos, trastornos obsesivo-compulsivos, entre otros. Aprobado desde 1991, se prescriben anualmente millones de recetas en el mundo. En general, la dosis inicial es de $50 \mathrm{mg}$ al día, con una titulación progresiva hasta una dosis de $200 \mathrm{mg}$. Los efectos adversos comunes incluyen: Somnolencia, dispepsia, náuseas, cefalea, aumento de la sudoración y, ocasionalmente, disfunción sexual ${ }^{3}$.

La hepatotoxicidad secundaria a sertralina se informó por primera vez en $1998^{4}$, con una prevalencia de $0,8 \%{ }^{5}$, siendo más frecuente la presentación como transaminitis asintomática de leve a moderada, que en general no requieren ajuste de dosis o suspensión, ya que son autolimitadas. Dentro de los casos moderados a graves, existen alrededor de 10 a 15 reportados en la literatura, entre los cuales hay manifestaciones de daño hepático con o sin ictericia, con un promedio de 2 a 24 semanas después del inicio del tratamiento, y con un patrón en el perfil hepático mixto, de daño hepatocelular y colestásico ${ }^{6}$; siendo la insuficiencia hepática fulminante muy infrecuente.

Respecto a la presentación fatal, hay un caso clínico de hepatitis aguda mortal en paciente de 54 años con alcoholismo crónico severo y síndrome de abstinencia, en el que inician tratamiento con sertralina 50 $\mathrm{mg}$ al día y presenta ictericia, somnolencia, asterixis y elevación de la bilirrubina total, con transaminasas hasta 1.000 , y eosinófilos elevados. Dentro de una semana de evolución, el TP disminuyó hasta que se hizo indetectable, no fue posible trasplantar y finalmente fallece; se realizó un estudio histológico con el hallazgo de necrosis extensa de los hepatocitos con colapso de la placa hepatocelular y marcado infiltrado inflamatorio ${ }^{7}$.

El mecanismo de las alteraciones hepáticas inducidas por la sertalina no se conoce con certeza, se propone que debido a su metabolismo por el citocromo P450 y también por el citocromo PYP 2D6 y 2B6, algunos de los intermediarios metabólicos 
podrían ser compuestos tóxicos responsables de los daños causados ${ }^{7}$. Otra teoría, presenta la posibilidad de que la sertralina pueda causar una alteración en el metabolismo mitocondrial a nivel hepático ${ }^{8}$, siendo así la responsable final de los trastornos observados.

El manejo de la hepatotoxicidad inducida por la sertralina consiste en un tratamiento de soporte, que incluye la hospitalización en una unidad de cuidado intensivo, el control estricto de los signos vitales, la corrección de trastornos hidroelectrolíticos y de la glucosa, descartar etiologías secundarias más frecuentes, control seriado de pruebas hepáticas, e incluso la realización de biopsia hepatica si el deterioro es rápido, también contempla la búsqueda de un trasplante hepático prioritario de acuerdo con la condición clínica; siendo esencial la suspensión del fármaco una vez que se tenga la sospecha clínica basada en algoritmos recomendados como el de Naranjo. Una recomendación importante es no reiniciar el medicamento porque pueden reaparecer los trastornos hepáticos ${ }^{9} \mathrm{y}$, si es necesario, el uso de antidepresivos se prefieren aquellos que pertenecen a otro grupo farmacológico (por ejemplo, bupropión, trazodona, entre otros).

De acuerdo con lo mencionado, y con los casos informados previamente, incluyendo el nuestro, el uso de la sertralina puede estar relacionado con la aparición de hepatotoxicidad, ya sea leve, moderada o severa; y al parecer una historia previa o actual de alteración hepática podría aumentar las posibilidades de presentar este efecto adverso. Por lo tanto, y aun cuando la Food and Drug Administration (FDA), considera que la preexistencia de daño hepático, es una precaución para el uso de sertralina, debería considerarse como una contraindicación relativa, especialmente en pacientes con daño hepático previo incluso con laboratorio normal y como clínicos considerar en estos contextos la disponibilidad de otros medicamentos antidepresivos con mecanismos de acción diferentes y sin estos efectos adversos reportados.

\section{Conclusión}

El uso de sertralina en raras ocasiones puede producir hepatotoxicidad, que incluso puede ser fatal. Cuando se usa este medicamento, se debe realizar un control de las pruebas hepáticas una vez que aparece la sintomatología y su interrupción inmediata, así como el uso de medidas de soporte intrahospitalarias. Los mecanismos por los cuales la sertralina induce estas complicaciones aún deben estudiarse, ya que son desconocidos tanto en pacientes sanos como en portadores de hepatopatías, con especial atención en este último grupo, debido a un probable aumento del riesgo.

\section{Referencias}

1.- https://livertox.nih.gov/Sertraline.htm

2.- Pfizer Inc. ZOLOFT(r). Disponible en: https://pfizer.com/products/productdetail/zoloft (consultado en enero de 2019).

3.- Khouzam HR, Emes R, Gill T, Raroque $R$. The antidepressant sertraline: a review of its uses in a range of psychiatric and medical conditions. Compr Ther. 2003;29:47-53.

4.- Hautekeete ML, Colle I, van Vlierberghe $\mathrm{H}$, Elewaut A. Symptomatic liver injury probably related to sertraline. Gastroenterol Clin Biol 1998; 22:

364-5.

5.- Información del producto. ZOLOFT ${ }^{\circledR}$ (sertraline hydrochloride) Tablets and Oral Concentrate, información de Pzifer Página 36. (consultado en enero de 2019).

6.- Li Wai Suen CFD, Boyapati R, Simpson I, Dev A. Acute liver injury secondary to sertraline. BMJ Case Rep. 2013:1-5.

7.- Fartoux-Heymann L, Hézode C, Zafrani
ES, Dhumeaux D, Mallat A. Acute fatal hepatitis related to sertraline. J Hepatol. 2001;35(5):683-4.

8.- Li Y, Couch L, Higuchi M, et al. Mitochondrial dysfunction induced by sertraline, an antidepressant agent. Toxicol Sci 2012;127:582-91.

9.- Persky S, Reinus JF. Sertraline hepatotoxicity: a case report and review of the literature on selective serotonin reuptake inhibitor hepatotoxicity. Dig Dis Sci 2003;48:939-44. 